\section{COMPLETE SYPHILITIC ALOPECIA}

\section{WITIY REPORT OF CASE *}

\section{LOYD THOMPSON, Ph.B., M.D.}

HOT SPRINGS, ARK.

Complete syphilitic alopecia is not mentioned by most textbooks, or it is dismissed with the statement that it is a rare condition.

Abraham and Davis ${ }^{1}$ state that "more cases than one" of complete syphilitic alopecia have come under their notice. Chambers ${ }^{2}$ presented a case before the Toronto Clinical Society, Nov. 14, 1900. His patient was a woman, aged 20 , whose hair began to fall at 5 , and again at 12 . At the age of 18 she was treated for interstitial keratitis. At the time of presentation there were only two hairs on the body, these being located on the anterior portion of the scalp.

In a review of the literature I have been unable to find mention of other cases, and therefore feel justified in reporting this case:

History.-J. F., man, aged 23, Jew, printer, admitted Oct. 2, 1914, had a negative family history. The mother died afier parturition. The father, brothers and sisters were negative. There was no history of baldness in the family. The paticni's past history was negative. In May, 1912, the patient had a chancre. The hair of the eyebrows began to fall out two weeks after the appearance of the chancre, the right side being first affected. Following this the hair of other regions began to fall out; in two months the body was entirely denuded. Three weeks following the appearance of the chancre the mouth was sore, and a rash appeared on the abdomen, back and left forearm. At this time the Wassermann reaction was strongly positive.

One week later the patient received an intravenous injection of salvarsan (dosage not known) and two more doses at weekly intervals. Following the second dose he had fever for four days. The patient came to Hot Springs in September, 1913, at which time he complained of headache, which was worse at night. He then received injections of mercury on alternate days for two weeks (dosage and salt not known) and 4 ounces of mercurial ointment by inunction. Potassium iodid was administered by mouth up to 150 grains per day for two weeks. From that time until admission to the hos. pital no treatment was administered. At the time of admission the patient complained of insomnia and nervousness.

Examination.-The most striking feature in this case was the absolutely complete alopecia, there not being a single hair on the entire body. No skin lesions were present and no scars. The epitrochlear glands on both sides were palpable. The inguinal glands were slightly enlarged, while the cervical glands were not palpable. The left tonsil was greatly hypertrophied with a denuded area covering one fourth of the surface. The right tonsil was only slightly hypertrophied. The pharynx was normal. The superficial veins of both legs showed slight vaticosity, while there was a varicocele of the left side. The pulse was 60 ; systolic blood pressure, 130 . The neurologic examination was negative. The urine was normal. The Wassermann test was negative. Lumbar puncture was refused.

Treatment.-The patient was placed on daily inunctions of $4 \mathrm{gm}$. of mercury, with potassium iodid by mouth up to 30 grains three times a day. He remained in the hospital until November 30 , and as no improvement was observed, was discharged.

This patient left Hot Springs, early in 1915, and returned in January, 1916, during which time he received no treatment. He still showed a condition of complete alopecia.

* From the Leo N. Levi Memorial Hospital.

1. Abraham and Davis, in Power and Murphy: System of Syphilis, London, 1910 , v, 100

2. Chambers, Graham: Alopecia Universalis, abstr., The JournaL A. M. A., Jan. 5, 1901, p. 57 .

\section{DIARSENOL VERSUS SALVARSAN}

\author{
JAMES A. GARDNER, M.D. \\ Fellow of the American College of Surgeons \\ BUFFALO
}

Since it has become impossible to procure salvarsan or neosalvarsan, many have turned to a substitute, diarsenol, manufactured by the Synthetic Drug Company of Toronto, Canada. The literature on this new preparation is meager, but apparently it differs only slightly from salvarsan.

I have used over 300 doses of diarsenol, employing the same technic that I did with salvarsan. Only three patients have experienced any reaction. This percentage compares favorably with the results I have had from salvarsan.

During 1914, and as long as it could be procured, I used neosalvarsan in preference to salvarsan, because less reaction followed its use. The injections were all intravenous. The method I follow in the use of salvarsan and of diarsenol is to dissolve a full dose $(0.6 \mathrm{gm}$.) in 15 c.c. of distilled water, neutralize with sodium hydroxid and then add to make the full amount, 20 c.c. If half doses are given, half the quantity of solution is used. The patients are given dosage in the office and are permitted to go home. The injection is usually given in the evening so that the patient may retire within the following hour.

If it is necessary with out of town patients to give injections during the daytime, they are advised to go to a hotel and lie down for five hours before returning home.

The average patient receives from ten to fifteen doses, depending on the stage of the case and on the strength of the Wassermann reaction. These are given every other day, beginning with a half dose and increasing the dosage so that the third is a full one of 0.6 gm., if no reaction occurs. By this method I seemingly have achieved very much better results than by giving the doses a week, two weeks or a month apart.

When I used salvarsan, patients would occasionally complain of nausea and vomiting following the injection, usually two or three hours after leaving the office. On two occasions, patients vomited while in the office.

In the administration of diarsenol, I have found a variation in the oxidation of the solution when made up. Some solutions remained a light color while others became dark almost immediately. The ampules which oxidized rapidly seemed to be those which caused the reaction, but not always so.

The histories which I give are of the cases in which considerable reaction and shock was experienced.

CASE 1.-F., man, aged 33, with history of infection ten years ago, had a +++ Wassermann reaction. $\mathrm{He}$ was given a $0.3 \mathrm{gm}$. and a $0.36 \mathrm{gm}$. dosage without any reaction. Immediately following the third dose of $0.42 \mathrm{gm}$. he began to have cold sweat, nausea, irregular pulse and all the evidence of shock. This lasted for about an hour, when he was able to go home. This ampule when mixed oxidized rapidly. Following this reaction no albumin or casts were found in the urine. Two days later he had a fourth dose of $0.3 \mathrm{gm}$. and continued with increasing dosage, $0.42,0.48,0.54,0.6$ and $0.6 \mathrm{gm}$. , and in the next dose we were able to inject only 0.48 $\mathrm{gm}$. when he again developed shock and had a return of the same symptoms experienced on the earlier occasion. This solution did not oxidize. He was given 15 minims of epi- 
Case 2.-Mrs. M., aged 37. Husband had been infected fifteen years before, and was told that time that it did not CASE 2.-Mrs. M., aged 37, whose husband had been infected fifteen years before, was told that time that it did not amount to anything, and received two or three weeks' treatment. He consulted me because of an orchitis. A Wassermann was taken showing +++ . He was given a series of ten doses of diarsencl and later brought his wife in for a blood examination. She was found to have $a+++$ Wassermann. The length of her history is indefinite. She was very nervous and had a fat arm. Because of this fact she was given $0.6 \mathrm{gm}$. injection of neosalvarsan intravenously and suffered no reaction. Two days later she was given $0.38 \mathrm{gm}$. of diarsenol, became nauseated and vomited after returning home. Two days following, $0.3 \mathrm{gm}$. of diarsenol was given. When she returned home she vomited for forty-eight hours, had a marked urticaria and was much prostrated. There was no oxidation of this solution. After ten days she returned for another dose. She was given $0.4 \mathrm{gm}$. of neosalvarsan, and had a return of the same symptoms, with not quite the degree of severity experienced after the previous injection of diarsenol. This treatment was stopped and she was placed on injections of mercuric salicylate intramuscularly. I think the experience in this case demonstrates that the patient had an idiosyncrasy for arsenic, and that any preparation of arsenic acted as an acute poison.

CASE 3.-G., man, aged 35, had infection, September, 1914. In December, 1914, and January, 1915, he was given two full doses of salvarsan. Jan. 29, 1915, he was given a full dose of neosalvarsan. March 1, 1916, he had a +++ Wassermann. March 3 he was given $0.3 \mathrm{gm}$. of diarsenol. This preparation oxidized very rapidly, and when administered, the patient had profound shock, sweating, weak and irregular pulse and vomiting, the symptoms lasting for about an hour. Fifteen minims of epinephrin were given. March 6 , he was given a dose of $0.3 \mathrm{gm}$., March 8, $0.48 \mathrm{gm}$, and March $10,0.48 \mathrm{gm}$. There was no oxidation of this solution. Following the last injection and while in the office the patient was nauseated and vomited. He stated that he had eaten a hearty dinner an hour and a half before, and had drunk two or three glasses of becr. Since that time he has had, March 15, 17 and 20, a dose each of $0.3 \mathrm{gm}$. without ensuing symptoms. March 23 , $0.48 \mathrm{gm}$. was given. This solution oxidized rapidly, and he had return of nausea, shock and weak, irregular pulse.

In reviewing these three cases in which unpleasant symptoms followed the use of diarsenol, I think the second would have trouble following any preparation of arsenic as demonstrated by her becoming ill after either diarsenol or neosalvarsan.

In the first case the patient was exceedingly nervous and worried, being fearful that some of the solution would get outside of the vein and make his arm sore. He had had such an experience previously, and he was also anxious to keep the fact that he was taking treatment secret from his family. I felt after his first sickness that it was largely psychologic, and still feel that inasmuch as he was able subsequently to take a number of doses without any effect, mental worry was a large contributing cause of his sickness.

The third patient had five doses of diarsenol without any reaction and three doses with marked reaction. In two of these injections there was considerable oxidation of the solution but not in the third.

In the use of diarsenol I believe the clinical results obtained and the elimination of the positive Wassermann compare very favorably with the use of salvarsan. Both of these preparations are more liable to be followed by nausea and shock than neosalvarsan.

I have noticed quite frequently that more or less oxidation occurred immediately on making the solution. As a rule, however, no more reaction was noticed after these injections than following those which remained clear. But in the cases in which reac- tion occurred, the majority had received a solution in which there had been more or less oxidation.

The same care, in preparation and technic, in intravenous injections, should be used with diarsenol as with salvarsan.

Electric Building.

\section{INJURY TO EYE FROM EXPLOSION OF GOLF BALL}

Edward J. Bernstein, M.D., Kalamazoo, Mich.

The patient, Anna N., aged 12, was first seen March 1, 1916. She complained of a severe burn of the right eye, caused the night before by the bursting of the core of a golf ball which had been used as a toy. There was great edema of the whole conjunctiva, completely enveloping the cornea, and the lids were greatly swollen. The eye had been very well washed by the family physician, Dr. Hawkey of Bloomingdale. I cleaned it with a mild acid solution $(1: 2,000$ hydrochloric acid) and put in 5 per cent. ethyl-morphin hydrochlorid (dionin) ointment with 2 per cent. atropin. Except for hot compresses of boric acid solution, this was the entire treatment. The eye has gone on to recovery with no symblepharon and only a slight central leukoma when the patient was last seen (March 21).

The idea of using mild acid solutions is indicated from the analysis of the contents of this particular kind of ball, as given by Dr. L. W. Crigler in the Ophthalmic Record (October, 1913) and in The Journal (April 26, 1913, p. 1297): a mixture of barium sulphate, sodium hydroxid and common soap. This should be borne in mind, as it is commonly supposed that the mixture is an acid one.

This is the second case which has come under my care in two years. In conversation with other physicians, I learned of similar cases, none of which were reported, as the men had no other idea than that they were altogether of too common occurrence to be noteworthy. Through the courtesy of Drs. Edward Jackson and F. Park Lewis, I have been able to find the following reports:

Capps, E. D.: Jour. Ophth. and Oto.-Laryng., vii, 85.

Carpenter, J. T., and Baer, B. F.: Pennsyliania Med. Jour., 1912, xvi, 228 .

Crigler, L. W.: Burn of Eyebal1 Due to Caustic Contents of Golf Ball, THE JoURNAL, April 26, 1913 , p. 1297.

Elliott, R. H.: Brit. Med. Jour., March 30, 1915.

Jessop, W. H. H.: Lancet, London, July 18, 1914, pp. 153, 171.
Langdon, F. W.: Ann. Ophth., January, 1913.

Lowell, Holbrook: Burn of Eyes from Contents of Golf Ball Core, THE JOURNAL, Dec. 27,1913 , D. 2302.

Murray, A. N.: Ophth. Rec., 1915 , xxiv, 637.

Nance, W. O.: Jour. Ophth. and Oto.Laryng., 1912.

Ohlemann: Klin.-therap. Wchnschr., xx, 604.

Posey, W. C.: Tr. Coll. Phys., Philadelphia, 1915, xxxvi, 327.

Suker, G. F.: Ophth. Rec., 1914, xxiii, 40.

Thomason, H. E.: Golf Ball Burn of Eye, The Journal, Sept. 20, 1913, p. 965

I am informed that the newer balls made in this country have no such dangerous cores, and that the various sporting journals and golf associations have posted notices warning of the danger attending attempts to open golf balls.

These accidents usually happen to children, and it is apparent that a repetition of the warning to the public is not out of place.

I shall be grateful for any further reports of similar cascs which physicians may send me.

A Protecting Ointment.-Dr. Frank H. Jackson of Houlton, Maine, recommends this ointment for cases in which prolonged drainage is required, as prostatectomies, cholecystostomy, pus appendicitis cases, etc., to protect the adjoining skin not only from maceration and excoriation but also from infection:

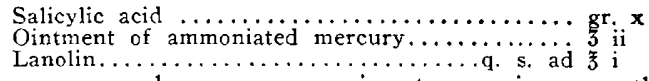

Every surgeon has seen occasion to require something of this protective nature, and a number of men use and recommend sterile petrolatum. The ointment can be sterilized in an autoclave, and kept ready in the hospital in jars for use as required. 